\title{
News Media Reporting on Substance Use Among People of African Ethnicity in Three Australian States, 2003-2013
}

\section{Danielle Horyniak}

Centre for Population Health, Burnet Institute and School of Public Health and

Preventive Medicine, Monash University

danielle@burnet.edu.au

\section{Megan SC Lim}

Centre for Population Health, Burnet Institute and School of Public Health and

Preventive Medicine, Monash University

lim@burnet.edu.au

\section{Peter Higgs}

Centre for Population Health, Burnet Institute, and School of Public Health and

Preventive Medicine, Monash University, and

Department of Public Health, La Trobe University

p.higgs@latrobe.edu.au

\begin{abstract}
The media play an important role in influencing public opinion and community discourse about health issues. Disproportionate reporting and misrepresentation of substance use issues among culturally and linguistically diverse groups can have adverse impacts on public perceptions of these communities. In the context of emerging media interest in substance use among African migrant communities, we examined the prevalence, characteristics and construction of print news media reporting related to substance use among people of African ethnicity. Relevant newspaper articles were identified through a systematic search of statewide, regional and local community newspapers in Victoria, New South Wales and Queensland between 2003 and 2013. Descriptive analyses of the key content of the articles were conducted, as well as a qualitative analysis of important themes and linguistic constructs within the articles. Fifty-seven unique articles were identified. The most commonly identified substance was alcohol, which was mentioned in $68 \%$ of the articles. Most articles
\end{abstract}


(81\%) described specific incidents, with the key issues relating to substance use being violence (mentioned in $47 \%$ of articles), crime (32\%) and drinkdriving (29\%). The refugee background of significant individuals in the incidents was emphasised, with these individuals constructed as either 'made vulnerable' by their refugee experiences and therefore deserving of sympathy, or as having a disregard for law and order and a lack of gratitude for the opportunities granted to them through migration to Australia, and thus deserving of punishment. Australian print media's portrayal of substance use among African migrants presents these communities as unaligned with Australian values, potentially marginalising them further. Continued efforts to address racism and discrimination at the interpersonal and structural levels are needed.

\section{Background $^{1}$}

Media play an important role in influencing public opinion and community discourse, including how health issues and health-related behaviours are perceived (Kline, 2006; Saguy, Frederick, \& Gruys, 2014; Wakefield, Flay, Nichter, \& Giovino, 2003). Alcohol and illicit drugs feature in thousands of articles in Australian print media each year (Azar et al., 2014; Hughes, Lancaster, \& Spicer, 2011), making this an important source of information about substance use for the general population (Fan, 1996). Lancaster et al. (2011) described four ways in which media can influence audiences in relation to substance use: agenda setting, framing of key issues, shaping individual and community attitudes, and influencing political debate and decision-making (Lancaster, Hughes, Spicer, MatthewSimmons, \& Dillon, 2011).

The media's role in shaping individual and community attitudes is particularly important in the context of alcohol and drug use among culturally and linguistically diverse (CALD) groups. In the past, disproportionate and sensationalised reporting of alcohol and illicit drug

\footnotetext{
${ }^{1}$ The authors would like to thank Mary Kangabe for assistance with literature searching. At the time this research was conducted, Danielle Horyniak was supported by an Australian Postgraduate Award, a Monash University Postgraduate Publications Award, and through funding from the National Health and Medical Research Council (NHMRC)-funded Centre for Research Excellence into Injecting Drug Use. Megan Lim is supported by an Australian Government Preventive Health Research Fellowship. The authors gratefully acknowledge the contribution to this work of the Victorian Operational Infrastructure Support Program. The funding bodies played no role in the study design, data analysis or preparation of the manuscript for publication. The authors have no conflicts of interest to declare.
} 
issues among CALD communities has had significant adverse impacts on these communities. For example, reporting of heroin use and trade among Vietnamese communities in Australia in the 1990s created the public perception that this community was not just the source of heroin, but the cause of the 'heroin problem' (G. Reid, Crofts, \& Beyer, 2001; G. Reid, Higgs, Beyer, \& Crofts, 2002; Teo, 2000). This led to significant stigmatisation of the Vietnamese community and, it has been argued, remains a continuing cause of disadvantage today (Evans, 2014; Jakubowicz, 2004).

There has been rapid growth in migration from Africa to Australia in the last two decades. Census data indicates that in 2011 approximately 290,000 Sub-Saharan African-born residents called Australia home, increasing from 209,000 in 2006, and more than double the population in 1991 (Australian Government Department of Immigration and Border Protection, 2014; Hugo, 2009). Although roughly half of this population is made up of skilled migrants from South Africa, a significant proportion is comprised of people from countries of Southern Africa and the Horn of Africa (e.g. Sudan, Somalia, Eritrea, Ethiopia) who migrated in the early-mid 2000s under Australia's Humanitarian Migration Program (Australian Government Department of Immigration and Citizenship, 2012; Hugo, 2009). There is a growing body of work documenting the resettlement challenges faced by refugees in Western countries such as Australia, in areas including language, education, employment, access to housing and services, and health (Fozdar \& Hartley, 2013; Morris, Popper, Rodwell, Brodine, \& Brouwer, 2009; Murray \& Skull, 2005). For recently-arrived African communities in Australia, many of these challenges are compounded by experiences of racism and discrimination, leading to further social and economic exclusion (Centre for Multicultural Youth, 2014; Colic-Peisker \& Tilbury, 2007; Fozdar \& Hartley, 2013, 2014; J. Marlowe, Harris, \& Lyons, 2013; J. M. Marlowe, 2010).

One arena identified by African communities as playing a role in perpetuating racism and discrimination is the media. African migrant groups, particularly young people, have been subjected to significant negative stereotyping in public media discourse, characterised as dangerous and violent, with gatherings of young people commonly described as 'gangs' (Centre for Multicultural Youth, 2014; Nunn, 2010; Windle, 2008). The 2007 murder of 18-year old Sudanese-Australian Liep Gony provides an important example. Despite the fact that Gony was the victim, not the perpetrator of the crime, media reports following Gony's death focused on 
violence and gangs, positioning Sudanese communities as dangerous outsiders within Australian society (Nunn, 2010).

Recently, alcohol and illicit drug use within African communities, and the Sudanese community in particular, have been identified as an emerging health concern (Ahmed, 2006; Ethnic Communities Council of Victoria, 2007; Khawar \& Rowe, 2013; Manton, Pennay, \& Savic, 2014). Since 2012, our research group has been developing a program of research exploring alcohol and drug use among African young people, with a particular focus on Melbourne's Western region, an important community hub (Horyniak, Higgs, Cogger, Dietze, \& Bofu, 2016; Horyniak et al., 2014; Papanastasiou, Higgs, \& Dietze, 2012). While conducting this research, we became aware of emerging media interest and reporting on these issues (E.g. Oakes, 2012; Petrie, 2012). Given the sensitivity and stigmatisation of drug and alcohol use among African communities (Browne \& Renzaho, 2010; Horyniak et al., 2014; Posselt, Galletly, de Crespigny, \& Procter, 2013), we became concerned about the potential impact of these articles on the communities identified. The work presented here aims to describe the prevalence, characteristics and construction of print news reporting related to substance use among people of African ethnicity in three Australian states, in order to assess whether these were isolated articles, or whether this was indicative of a potentially damaging emerging trend in reporting.

\section{Methods}

A systematic search of state-wide, regional and local community newspapers from the three most populous states, Victoria, New South Wales and Queensland, over the period 1 January 2003 to 31 December 2013 was conducted using two electronic databases (Newsbank and Factiva). Table 1 summarises the newspapers searched and the availability of data from different sources across the period of interest. The search strategy incorporated terms relating to alcohol and illicit drug use, African ethnicity and migration (Table 2). Broad search terms were used in addition to a number of specific substance terms. These terms were selected because they are the most commonly used substances in the general Australian population (Australian Institute of Health and Welfare, 2013) and emerging evidence suggests they are also being used by African migrant communities. Article headlines and lead paragraphs only were searched for these terms as, due to their wide applicability, searching entire articles identified too many irrelevant articles (e.g. articles concerning alcohol consumption by African sportspersons). Full-text articles were then 
retrieved and reviewed, with all articles which made any mention of alcohol or illicit drug use among person/s of African ethnicity residing in Australia selected for inclusion. All searches and initial classification of articles were conducted by Danielle Horyniak; to ensure reliability of the coding, the second author (Megan Lim) assessed a random 10\% of articles. Discordant classifications $(<5 \%)$ were resolved through discussion.

Table 1. Newspaper sources, location and availability

\begin{tabular}{|c|c|c|c|}
\hline State & $\begin{array}{c}\text { Publication } \\
\text { type }\end{array}$ & $\begin{array}{l}\text { Number } \\
\text { of } \\
\text { sources } \\
\text { searched }\end{array}$ & Dates available \\
\hline \multirow[t]{3}{*}{ Victoria } & State-wide & 2 & Jan 2003 - Dec 2013 \\
\hline & $\begin{array}{l}\text { Major regional } \\
\text { centre }\end{array}$ & $\begin{array}{l}1 \\
4 \\
1 \\
1\end{array}$ & $\begin{array}{l}\text { Sep } 2003 \text { - Dec } 2013 \\
\text { Jan } 2011 \text { - Dec } 2013 \\
\text { May } 2011 \text { - Dec } 2013 \\
\text { Aug } 2011 \text { - Dec } 2013\end{array}$ \\
\hline & Local & 49 & Varied \\
\hline \multirow{3}{*}{$\begin{array}{l}\text { New South } \\
\text { Wales }\end{array}$} & State-wide & 2 & Jan 2003 - Dec 2013 \\
\hline & $\begin{array}{l}\text { Major regional } \\
\text { centre }\end{array}$ & $\begin{array}{l}2 \\
1 \\
3 \\
2\end{array}$ & $\begin{array}{l}\text { Jan } 2003 \text { - Dec } 2013 \\
\text { Mar } 2008 \text { - Dec } 2013 \\
\text { Jan } 2011 \text { - Dec } 2013 \\
\text { Apr } 2011 \text { - Dec } 2013\end{array}$ \\
\hline & Local & 128 & Varied \\
\hline \multirow[t]{3}{*}{ Queensland } & State-wide & 1 & Jan 2003 - Dec 2013 \\
\hline & $\begin{array}{l}\text { Major regional } \\
\text { centre }\end{array}$ & $\begin{array}{l}1 \\
6\end{array}$ & $\begin{array}{l}\text { Dec } 2006 \text { - Dec } 2013 \\
\text { Aug } 2008 \text { - Dec } 2013\end{array}$ \\
\hline & Local & 95 & Varied \\
\hline
\end{tabular}

Variables relating to article identification (publication title, article title, journalist name, article type, publication date) and content (article framing and tone, communities identified, consequences of substance use identified, sources [individuals or organisations cited in the article as giving information or opinions]) were extracted into a Microsoft Access database. Coding categories for article content were defined a priori, and were informed by previous media reviews of substance use issues (Gelbart, 2012; 
Hughes et al., 2011). Descriptive analyses of key variables were conducted using Stata Version 11.1 (Statacorp LP, TX, USA).

We then aimed to examine how the articles were constructed, and to identify key themes and prominent terminology within the articles. To do this, we employed a qualitative methodological approach, influenced by discourse analysis (Gee, 2011) and content analysis (Vaismoradi, Turunen, \& Bondas, 2013). An open coding process was conducted focusing on two primary questions: How is/are the key actor/s in the event portrayed? How is substance use portrayed within the context of the actor's life experiences? Articles were coded using Nvivo Version 10 (QSR International, Doncaster, Australia).

\section{Table 2. Search Terms}

(migrant* or refugee* or "asylum seeker" or Africa* or Sub-Sahara* or Algeria* or Angola* or Benin* or Botswana or Batswana or Motswana or "Burkina Faso" or Burkinese or Burkinabe or Burundi* or Cameroon* or Cape Verd* or "Central African Republic*" or Chad* or Comoros or Comoran or Congo* or "Democratic Republic of Congo" or "Ivory Coast” or Ivorian or Djibouti* or Egypt* or Equatoguinean or Eritrea* or Ethiopia* or Gabon* or Gambia* or Ghana* or Guinea* or Guinea-Bissau* or Kenya* or *Lesotho or Basotho or Mosotho or Liberia* or Libya* or Madagasc* or Malagasy or Malawi* or Mali* or Maurit* or Morocc* or Mozambiqu* or Mozambican or Namibia* or Niger* or Rwanda* or "Sao Tome" or Senegal* or Seychell* or "Sierra Leone*" or Somali* or Sudan* or Swazi* or Tanzania* or Togo* or Tunisia* or Uganda* or Zambia* or Zimbabwe*)

and (alcohol* or drink* or drunk* or drank or khat or qat or ghat or chat or smok* or sniff* or chew* or booze or drug* or intoxic* or illicit or substance* or inject* or junk* or cannabis* or marijuana or methamphetamine or amphetamine or (speed and drug) or (ice and drug))

\section{Results}

\section{Article characteristics}

In total, 57 unique articles were identified. The number of relevant articles published each year ranged from one to 11, with no discernible trend in reporting over time. The majority of the articles were published in Victorian newspapers (62\%), and more than half (54\%) were published in major state-wide newspapers (Table 3). Articles predominantly reported on events occurring within the state in which the article was published, although six articles (11\%) had no specific geographic focus (Table 4). The articles described news events related to a range of topics including drink-driving incidents, incidents of property damage and interpersonal violence 
Table 3. Article publication characteristics

\begin{tabular}{lr}
\hline Characteristic & $\mathbf{N}=\mathbf{5 7}$ \\
$\mathbf{n}(\mathbf{\%})$ \\
\hline Newspaper type & \\
State-wide & $30(53)$ \\
Major regional & $9(16)$ \\
Local & $18(32)$ \\
Article type & \\
News & $55(97)$ \\
Other & $2(3)$ \\
Page number & \\
One & $3(5)$ \\
Two-Four & $8(14)$ \\
Five or later & $38(67)$ \\
Unknown & $8(14)$ \\
Article framing & \\
Episodic (focus on a single event) & $46(81)$ \\
Thematic ('big picture') & $11(19)$ \\
\hline
\end{tabular}

Table 4. Article content characteristics

\begin{tabular}{|c|c|}
\hline Characteristic & $\begin{array}{l}\mathrm{N}=57 \\
\mathrm{n}(\%)\end{array}$ \\
\hline \multicolumn{2}{|c|}{ Primary city of focus } \\
\hline Melbourne & $31(54)$ \\
\hline Sydney & $10(18)$ \\
\hline Brisbane & $1(2)$ \\
\hline Not specific & $6(11)$ \\
\hline Other & $9(15)$ \\
\hline \multicolumn{2}{|c|}{ African community mentioned ${ }^{1}$} \\
\hline Eritrean & $2(4)$ \\
\hline Ethiopian & $4(7)$ \\
\hline Nigerian & $3(5)$ \\
\hline Somali & $5(9)$ \\
\hline Sudanese & $29(51)$ \\
\hline Tanzanian & $5(9)$ \\
\hline Ugandan & $1(2)$ \\
\hline Zimbabwean & $3(5)$ \\
\hline 'African’'2 & $16(28)$ \\
\hline
\end{tabular}




\begin{tabular}{lr}
\hline Characteristic & $\mathrm{N}=57$ \\
$\mathrm{n}(\%)$ \\
\hline
\end{tabular}

\section{Substance of concern ${ }^{1}$}

Alcohol

$39(68)$

Cannabis

Heroin

$0(0)$

Khat

Methamphetamine

No specific substances mentioned

Other $^{3}$

Consequences of substance use ${ }^{1}$

Violence

$27(47)$

Property crime

Crime (not further specified)

$18(32)$

Sexual assault

Mental health issues

Social issues ${ }^{4}$

Drink-driving/road trauma

$17(29)$

Other $^{5}$

Number of sources cited

None

$18(32)$

One

$18(32)$

Two or more

Source type ${ }^{1}$

$21(38)$

$N=39$

African Community Organisation Representative

$18(46)$

Consumer

$5(13)$

Health Professional

Legal Representative/Magistrate

$9(23)$

Non-government organisation/Advocacy Group

$2(5)$

Police

$12(31)$

Politician/Government Rep/Local MP

$9(23)$

Researcher/Academic

Welfare/Social/Community Worker

${ }^{1}$ Not mutually exclusive; ${ }^{2}$ Includes: 'East African', 'West African', 'Horn of Africa';

${ }^{3}$ Includes: cocaine, ecstasy, paint; ${ }^{4}$ E.g. homelessness, unemployment; ${ }^{5} \mathrm{E} . g$.

Dependence, general health problems. 
occurring while under the influence of alcohol or drugs, and arrests related to drug importation and sales. The most common consequences of substance use referred to in articles were violence (mentioned in $47 \%$ of articles), crime (32\%), drink-driving/road trauma (29\%) and social issues, such as homelessness and unemployment (16\%). Only six (10\%) articles examined health-related consequences of substance use. The most common substance of concern was alcohol, mentioned in two thirds of articles (68\%; Table 4). Cannabis and Khat (a native African plant which produces a mild stimulant effect) were each mentioned in $7 \%$ of articles and methamphetamine was mentioned in $5 \%$ of articles. Half of all articles specifically identified the Sudanese community or Sudanese individuals (51\%), with smaller numbers of articles referring to any other specific communities. One third of articles referred broadly to "African" communities or individuals.

Two-thirds of articles cited at least one source, with the most commonly cited sources being African community organisation representatives (46\%), police (31\%), legal representatives or magistrates (23\%) and politicians or Government representatives (23\%; Table 4). Few articles cited people who consumed alcohol or drugs (13\%), health professionals (3\%) or academics (3\%).

\section{Prominence of ethnic and 'refugee' identities}

Individuals in the news stories were commonly identified according to their ethnic background and/or 'refugee' status. For example, descriptions such as “a Somalian refugee”, “a Sudanese-born Melbourne man”, "a drunken refugee”, or "youths of African origin" were typical. Though the authors may have seen these descriptors as a way of providing context to the story, references to refugee status and experiences contribute to a sense of alienation and identify these actors as the 'ethnic other' (Essed, 2001; Grove \& Zwi, 2006; Hatoss, 2012). The refugee label has been used in two different ways in the articles identified in this study. First, this label has been used to construct 'the refugee' as helpless, vulnerable and traumatised (J. M. Marlowe, 2010; M. Phillips, 2011; Zetter, 2007). In this way, the individual is portrayed as a 'good person' who is capable of redemption, and, by virtue of their traumatic and troubled life, should not be held responsible for their actions. For example, in an article about staff at a notfor-profit restaurant, Issiah Lado was characterised as a "child refugee" (not only vulnerable and traumatised, but above all, innocent) who, despite having "experimented with drinking and fighting”, had "taken a very long journey... rebuilding lives disrupted by conflict and forced family 
separation” (Jackson, 2007). Similarly, a young Sudanese man who stabbed a friend following "an extreme drinking session" was described as having been "born into war" (Petrie, 2012).

This construction of refugee identity was particularly evident in a number of articles describing the trial of Taban Gany, who crashed his car into a primary school while driving under the influence of alcohol, injuring several children. As shown below, although Gany's behaviour is deemed reckless, his refugee identity is used to justify his actions, portraying him as deserving of sympathy and pity, both from the justice system, and from the Australian public:

A Sudanese refugee who was drunk when he ploughed his car into a schoolyard, injuring young children, has been jailed... Gany arrived in Australia in January 2004 from a United Nations refugee camp in Kenya, having lived there for about nine years after fleeing Sudan in fear of persecution. (Berry \& Burrow, 2006)

In sentencing Gany, Judge Gebhardt said the refugee had suffered post-traumatic stress disorder and had developed an alcohol problem after fleeing the civil war in Sudan. (Masanauskas \& Mickelburough, 2006)

The tribunal heard that Mr Gany, who fled Sudan after his father was tortured and murdered, was diagnosed in 2005 as suffering an 'adjustment disorder with mixed anxiety and depressed mood’. (Munro, 2010)

By contrast, several other articles framed the 'refugee' identity in the opposing direction, constructing refugees as 'bad citizens', ungrateful for the opportunities afforded to them in Australia and having a blatant disregard for law and order. One incident, which was the subject of five articles, involved a Tanzanian national who was arrested for allegedly offering drugs to two schoolgirls in exchange for sex. As the following quotes demonstrate, this incident was portrayed as a predatory attack on innocent children, and an affront to Australian values, leading to calls for the individual involved to be deported:

Parents are incensed a Tanzanian national, who offered drugs to 
two Sydney schoolgirls in exchange for sex, is still in the country. (Carswell, 2006)

Instead of being sent home on the next plane, Salum was slapped on the wrist with 250 hours community service... He still lives in the city and is free. (McIlveen, 2006)

A significant number of included articles focused on incidents of alcohol-related violence, particularly among young people. Again, within these articles, individuals were portrayed as having a disregard for law and order, with such descriptions used as a "wild brawl”, "ethnic warfare”, and "a culture of violence imported to this country". One article reported that police officers had to "pull on disposable gloves" before arresting an intoxicated man (Oakes, 2012), while another stated that "a Somalian refugee spat at, kicked and scratched police"("Police assaulted by drunk," 2004) Such language evokes a vision of the 'wild', untameable Africans of colonial stereotypes (M. Phillips, 2011).

\section{Substance use as a moral and legal concern}

As noted in the quantitative data analysis, many of the articles focused on violence and crime as consequences of substance use, while few addressed health or social issues, either as a factor underlying substance use, or as a consequence of substance use. Further, articles were presented within a moral and legal discourse, where, rather than seeking to provide individuals with support services to address their substance use, legal and justice responses were emphasised. This frames people 'as a problem', rather than as 'people with a problem'. This discourse is particularly strongly reflected in the choice of sources cited within the articles; as noted above, the voices of the criminal justice system were prioritised over health professionals and academics, and the drug and alcohol consumers themselves.

Although almost half of the articles cited an African community organisation representative, the types of quotes used repeatedly frame isolated incidents for which an individual is responsible as problems for which the entire community was accountable:

'We, the Sudanese community, are very sorry for the accident where the little boy lost his leg' he said. 'We need the public to know that the accident was not intentionally done by the driver.' [Quote from Samuel Kuot, Victorian Sudanese Community 
President] (Ross, 2006)

David Manyok, head of the Maroondah Southern Sudanese Christian Welfare Association, was surprised to hear about the brawl. 'Nothing like this has happened before,' he said... 'We are friends to all residents of Maroondah and don't want to have problems with anyone in our city’. (Ebrington, 2011)

\section{Discussion}

This study documents patterns of print news media reporting among people of African ethnicity in three Australian states over the past decade. Despite concerns about increasing reporting, the number of articles published annually fluctuated and no increasing trend was observed over time. There were however a substantially higher number of stories focused on Melbourne and printed in Victorian newspapers compared with the other states examined. Given that Sydney and Melbourne have similar sized populations of African migrants (Australian Bureau of Statistics, 2008) and there is no evidence to suggest a greater number of incidents occur in Melbourne compared with Sydney (for example, offending rates for homicide, acts intended to cause injury, robbery, and public order offences are actually higher in Sydney (Australian Bureau of Statistics, 2015)), this suggests a greater interest in these stories in Victoria compared with other states. Our analysis found that alcohol-related stories were most common (comprising 68\% of articles) and that articles related to violence and crime comprised a significant proportion of the reporting (47\% and 32\% of articles, respectively). The prominence of stories related to violence and crime is consistent with both alcohol and drug reporting more generally (Azar et al., 2014; Lancaster, Hughes, \& Spicer, 2012; Nicholls, 2011), and news stories involving ethnic minority communities more broadly, where crime-related stories have been shown to comprise a higher percentage of news stories compared with news stories reporting on Anglo-Celtic communities (G. Phillips, 2009).

Despite finding fewer articles than we anticipated, several issues of concern were noted in the way these news stories were presented. In newspaper articles, space is extremely limited, so headlines and lead paragraphs are constructed to convey maximum information in minimum words. Despite being of no direct relevance to the event concerned (e.g. a drink-driving incident), individuals were commonly identified by their ethnic or refugee status. This suggests that journalists' and/or editors' choice to emphasise ethnic identity and refugee status is an intentional one. 
This editorial choice has been noted in research examining reporting on African youth in Australia, which found that racial and migration attributes are emphasised and juxtaposed against the dominant community. In contrast, the dominant community is rarely explicitly referred to as white or Australian, but rather as 'locals', 'residents' or simply, 'the community' (Windle, 2008). In emphasising ethnic and refugee status, journalists/editors are alienating the individual concerned, drawing attention to their 'otherness', and portraying them as inherently 'UnAustralian'.

Importantly almost one third of articles grouped together people from different geographic regions, races, ethnicities and religions as 'African', which, suggests that they all share common attributes and behaviours, and fails to acknowledge their diverse identities (Ndlovu-Gatsheni, 2010). Again, this contributes to a sense of alienation and othering, through discourse which positions 'them' as all alike, and thus unlike 'us' (us being the dominant Anglo-Australian population). Failure to acknowledge the socio-political and cultural diversity of African communities has recently been highlighted as an ongoing form of oppression (Bayou, 2016; Mapedzahama \& Kwansah-Aidoo, 2013). Although this may, in part, reflect the relative newness of these communities in Australia, evidence also shows that a significant proportion of Australians continue to express ambivalence towards immigration and multiculturalism, particularly in relation to some specific minority groups such as Muslims and darkskinned communities (Markus, 2013; Scanlon Foundation, 2016), impacting the potential for new migrant communities to feel genuinely included.

The emphasis on refugee background in particular was used to construct individuals involved as either traumatised victims, deserving of pity and sympathy, or 'bad citizens' with a blatant disregard for law and order. Underlying both these categorisations (ethnic identity and refugee status) is the alienation and othering of migrant communities, and the suggestion that migrants to Australia benefit more from being here, than we as a nation do from hosting them. This is consistent with findings from a review examining how forced migrants are received in Western nations, which noted that forced migrants are commonly presented as a threat and an imposition on host communities, and rarely portrayed as having skills or assets to contribute to their new communities (Grove \& Zwi, 2006).

Such a discourse contributes to the marginalisation of migrant communities. For example, othering has been shown to limit opportunities in areas including education, labour participation, and building of social and 
cultural capital (Colic-Peisker \& Tilbury, 2007; Fozdar \& Hartley, 2014; Morgan \& Idriss, 2012; Viruell-Fuentes, Miranda, \& Abdulrahim, 2012; Wright, 2010). In addition to social and economic disadvantage resulting from these constrained opportunities, othering of migrant communities also plays an important role in health inequality. For example, it has been linked to restricted access to health services and barriers to service utilisation, resulting in late or non-presentation and increasing the risk of adverse health outcomes (Castañeda et al., 2015; Grove \& Zwi, 2006). Further work is required to explore the complex pathways between othering and health service utilisation and health inequality, and to inform evidence-based strategies to address its harmful effects.

The selection of sources used for commentary in the articles identified is also of concern. Selection of sources has been noted as a way to provide insight into the journalists' framing of a news story and hence the story's agenda (Nicholls, 2011). The silencing of affected individuals and alcohol or drug consumers within the stories identified here contributes to their disempowerment, suggesting that their voices are not worthy of being heard. This is consistent with broader evidence suggesting that alcohol and drug consumers are often excluded from discussions which concern them (Madden, 2008; McDonald, 2014). Further, the overrepresentation of law enforcement sources reinforces a criminal discourse, a finding which has been shown in broader analyses of alcohol and drug-related media reporting (Azar et al., 2014; Hughes et al., 2011). Attempts to engage community organisations (as cited in approximately half of the articles) are encouraging, but community organisation representatives may not represent the views of all community members, particularly the marginalised young people who are most likely to be using alcohol and illicit drugs. Further, there appears to have been some selective use of community organisations as sources, whereby quotes from community representatives commonly emphasised their commitment to being 'good citizens' by accepting collective responsibility for individual actions. As has been noted in previous research (Windle, 2008) this notion of collective responsibility supports a discourse of cultural difference and exclusion. It is unclear why community representatives may feel the need to accept collective responsibility, however research conducted in regional Australia noted that some refugees perceived journalists as being closely linked to government, causing them to censor their public comments for fear of repercussions (Richards, 2014). This raises concerns about refugee communities' vulnerability in engaging with media, and highlights the importance of the journalist's responsibility to give a voice to affected communities, while at 
the same time considering the potential impact of selecting to publish quotes which emphasise collective responsibility. Media training for representatives of community organisations may also be worthwhile.

Overall, the framing of articles identified emphasises substance use as a legal and moral issue, rather than a health issue. Placing blame on individuals and communities, and prioritising criminal justice responses does not address the underlying causes of substance use. While the legal and moral framing of news reporting on alcohol and drug use has also been shown in broader reviews of reporting (i.e. not focused on CALD communities) (Azar et al., 2014; Hughes et al., 2011; Lancaster et al., 2012), the potential implications for CALD communities are particularly worrisome. Combined with sensationalised media reporting on African crime and gangs, the type of reporting identified in this review has significant potential to contribute to negative stereotyping and marginalisation of African migrant communities, potentially contributing to social and economic exclusion.

It is also important to consider this moral framing within the broader context of Australian drinking culture and public discourse around alcohol consumption. Our media analysis found that African-background community members who have placed others at risk while under the influence of alcohol were constructed as 'wild' and 'un-Australian', and have the legitimacy of their citizenship and belonging questioned. This is somewhat of a contradiction given that engaging in excessive drinking can be seen as adhering to prevalent Australian norms. There is considerable evidence to suggest that drinking alcohol is accepted as a social norm in Australia, with around $80 \%$ of the population reporting consuming alcohol in the past year (Australian Institute of Health and Welfare, 2013; Foundation for Alcohol Research and Education, 2015). Consuming alcohol, often to excess, is commonly considered a part of Australian culture; it is used to both celebrate and commiserate, and is expected and encouraged in a wide variety of social and public settings (Allan, Clifford, Ball, Alston, \& Meister, 2012; M. Reid, Farrelly, Farrell, Fry, \& Worsley, 2013; Roche et al., 2009). Importantly, one fifth of Australian drinkers report having put themselves or others at risk while under the influence of alcohol in the past year, through activities such as drink-driving, verbally abusing someone or creating a disturbance (Australian Institute of Health and Welfare, 2013). Interestingly, recent research has shown that almost all drinkers describe themselves as "responsible drinkers" (Foundation for Alcohol Research and Education, 2015), and the Australian public is most supportive of structural alcohol controls rather than controls which impact 
individual drinking behaviour (Tobin, Moodie, \& Livingstone, 2011). Together, this suggests that the perception is that it is always 'others' who are responsible for alcohol-related problems. It is possible that the media is (either intentionally or unintentionally) reflecting these perceptions and reinforcing dominant discourses, by presenting African migrant communities as one part of this 'other' who is responsible for alcoholrelated problems.

This study has several important implications. Increasing cross-cultural training in the journalism, media and communications sectors is not a new or novel suggestion (Deuze, 2001), however findings from this study reemphasise its importance, particularly in relation to sensitive issues such as substance use. A 2011 review of curricula for journalism courses at four major Australian universities found that none included core subjects focused on ethnicity, diversity or multiculturalism (van Dijk, 2011). This suggests more training is required. The review, which also found similar findings across the US, Canada and Europe, recommends a broad range of areas which should be covered in such training, including ethnic studies, and practical training on news gathering and writing in relation to ethnic communities, such as how to assess newsworthiness, how to find and contact ethnic organisations and select diverse sources, and how to avoid stereotyping (van Dijk, 2011). Some relevant work is already being conducted in Australia, such as the 'Reporting Diversity' project, which aims to improve understanding of the links between media reporting and community perspectives of multiculturalism and diversity, and develop tools and resources for media practitioners and students to improve their reporting practices (G. Phillips, ND). Based on our findings, we recommend that training should also focus specifically on reporting of news stories which feature issues which are particularly sensitive for CALD communities, such as substance use. Such training should promote the framing of these issues within a health discourse rather than a legal or moral discourse, and should encourage journalists to refrain from focussing on ethnic or migration backgrounds in news articles where it is not relevant to the 'newsworthy' aspect of the story.

There is also a need for increased interaction between the media sector and alcohol and other drugs researchers and service providers. We acknowledge that journalists' choice of sources for stories may be influenced by availability and access (Nicholls, 2011). Building ongoing relationships with alcohol and other drugs experts will enable journalists to access appropriate expert sources as needed, resulting in the writing of more balanced and informed articles. Importantly, research shows that 
public health researchers consider engaging with the media to ensure accurate reporting and appropriate framing of health issues an important component of their role (Chapman et al., 2013), suggesting they would be interested and willing to develop these ongoing relationships with media partners.

This study has some limitations which must be acknowledged. Some sources were not available across the entire period of interest due to university library restrictions, so it is possible that some relevant articles were not identified. We have no reason to believe that excluded articles would systematically differ from those included, limiting the impact of selection bias. In addition, the precision of search terms was limited as only article headlines and lead sentences were searched. As noted in the methods section, it would not have been feasible to broaden our search to complete articles. It is possible that this selection process biased results through missing articles which may have been more positively focused and mentioned recovery from alcohol/drugs later in the article. Similarly, we did not include articles examining substance use among non-African communities in our methodological approach as previous studies of this nature have been recently conducted (Azar et al., 2014; Gelbart, 2012; Hughes et al., 2011) and we were limited in time and resources to conduct this work. We acknowledge that this limits our ability to effectively compare our findings to other communities.

\section{Conclusion}

Although no significant temporal trends in reporting of alcohol and drug-related news stories among African migrant communities were identified in our study, our findings show that articles prioritise a legal and moral discourse rather than a health discourse, and construct African communities as unaligned with Australian values. This has the potential to further marginalise these communities and exacerbate the harms of alcohol and other drug use. Strategies to educate journalists on culturally competent reporting around sensitive issues such as substance use are required. This includes approaches that build ongoing relationships between journalists, ethnic-based community organisations, and alcohol and other drug experts. Media training for representatives of community organisations, particularly regarding issues around notions of collective responsibility, may also be warranted. This may go some way toward providing better informed media coverage on issues that are socially complex, like alcohol and other drug use. Continued efforts to address racism, discrimination and othering at the interpersonal and structural levels are also needed. 


\section{Bibliography}

Ahmed, B. (2006). Report of the African-Australian Community's initiative workshop on issues affecting the resettlement of Africans. Melbourne: African Think Tank Inc.

Allan, J., Clifford, A., Ball, P., Alston, M., \& Meister, P. (2012). 'You're Less Complete if You Haven't Got a Can in Your Hand': Alcohol Consumption and Related Harmful Effects in Rural Australia: The Role and Influence of Cultural Capital. Alcohol and Alcoholism, 47(5), 624-629.

Australian Bureau of Statistics. (2008). Census 2006: People born in Africa. 3416.0 Perspectives on Migrants, 2008. Canberra: Australian Bureau of Statistics.

Australian Bureau of Statistics. (2015). 4519.0 - Recorded Crime Offenders, 2014-15. Canberra: Australian Bureau of Statistics.

Australian Government Department of Immigration and Border Protection. (2014). The people of Australia: Statistics from the 2011 census. Canberra: Australian Government Department of Immigration and Border Protection.

Australian Government Department of Immigration and Citizenship. (2012). Population flows: Immigration aspects, 2010-11 edition. Canberra: Australian Government Department of Immigration and Citizenship.

Australian Institute of Health and Welfare. (2013). National Drug Strategy Household Survey: Detailed Report. Drug statistics series no. 28. Cat. no. PHE 183. Canberra: AIHW.

Azar, D., White, V., Bland, S., Livingston, M., Room, R., Chikritzhs, T., Wakefield, M. (2014). 'Something's brewing': The changing trends in alcohol coverage in Australian newspapers 2000-2011. Alcohol and Alcoholism, 49(3), 336-342.

Bayou, R. (2016). Stereotyping of Africans is everywhere, but Australians are particularly clueless The Guardian. http://www.theguardian .com/commentisfree/2016/mar/08/stereotyping-of-africans-iseverywhere-but-australians-are-particularly-clueless

Berry, J., \& Burrow, V. (2006, 8 July 2006). Drunk driver jailed over school crash, The Age, p. 5. http://www.theage.com.au/ news/ national/drunk-driver-jailed-over-school-crash/2006/07/07/ 1152240491111.html

Browne, J., \& Renzaho, A. (2010). Prevention of alcohol and other drug problems in culturally and linguistically diverse communities. Melbourne: DrugInfo Clearinghouse. 
Carswell, A. (2006, 17 March 2006). Parents ask: why is he here?, Daily Telegraph, p. 8.

Castañeda, H., Holmes, S. M., Madrigal, D. S., Young, M. E. D., Beyeler, N., \& Quesada, J. (2015). Immigration as a Social Determinant of Health. Annual Review of Public Health, 36(1), 375-392.

Centre for Multicultural Youth. (2014). Fair and Accurate? Migrant and refugee young people, crime and the media. Carlton: Centre for Multicultural Youth.

Chapman, S., Haynes, A., Derrick, G., Sturk, H., Hall, W. D., \& St. George, A. (2013). Reaching "An Audience That You Would Never Dream of Speaking To": Influential Public Health Researchers' Views on the Role of News Media in Influencing Policy and Public Understanding. Journal of Health Communication, 19(2), 260-273.

Colic-Peisker, V., \& Tilbury, F. (2007). Integration into the Australian Labour Market: The Experience of Three "Visibly Different” Groups of Recently Arrived Refugees. International Migration, 45(1), 59-85. Deuze, M. (2001). Journalism education and multiculturalism: Enhancing the curriculum. Asia Pacific Media Educator, 10, 127-147.

Ebrington, M. (2011, 3 May 2011). 'No strains' with Sudanese, Maroondah Journal.

Essed, P. (2001). Multi-identifications and Transformations: Reaching Beyond Racial and Ethnic Reductionisms. Social Identities, 7(4), 493-509.

Ethnic Communities Council of Victoria. (2007). Horn of African and Sudanese communities in Victoria. Carlton: Ethnic Communities Council of Victoria.

Evans, R. (2014). Applying the theory of resource curse to disadvantaged migrant communities and criminal offending: Vietnamese Australians and the heroin trade as a case study. Melbourne: Deakin University.

Fan, D. P. (1996). News Media Framing Sets Public Opinion That Drugs is the Country's Most Important Problem. Substance Use and Misuse, 31(10), 1413-1421.

Foundation for Alcohol Research and Education. (2015). Annual Alcohol Poll 2015. Deakin West: Foundation for Alcohol Research and Education.

Fozdar, F., \& Hartley, L. (2013). Refugee resettlement in Australia: what we know and need to know. Refugee Survey Quarterly, 32(3), 23-51.

Fozdar, F., \& Hartley, L. (2014). Civic and Ethno Belonging among Recent Refugees to Australia. Journal of Refugee Studies, 27(1), 126-144. 
Gee, J. P. (2011). An introduction to discourse analysis: Theory and method (3rd edition). New York: Routledge.

Gelbart, L. H. (2012). Media reporting on alcohol and violence in Victoria since 2005 (Unpublished thesis, BBiomed Honours).

Grove, N. J., \& Zwi, A. B. (2006). Our health and theirs: Forced migration, othering, and public health. Social Science and Medicine, 62(8), 1931-1942.

Hatoss, A. (2012). Where are you from? Identity construction and experiences of 'othering' in the narratives of Sudanese refugeebackground Australians. Discourse \& Society, 23(1), 47-68.

Horyniak, D., Higgs, P., Cogger, S., Dietze, P., \& Bofu, T. (2016). Heavy alcohol consumption among marginalised African refugee young people in Melbourne, Australia: Motivations for drinking, experiences of alcohol-related problems, and strategies for managing drinking. Ethnicity and Health, 21(3), 284-299.

Horyniak, D., Higgs, P., Cogger, S., Dietze, P., Bofu, T., \& Seid, G. (2014). Experiences of and attitudes towards injecting drug use among marginalised African migrant and refugee youth in Melbourne, Australia Journal of Ethnicity in Substance Abuse, 13(4), 405-429.

Horyniak, D., Higgs, P., Degenhardt, L., Cogger, S., Power, R., \& Dietze, P. (2012). Injecting drug use and related health behaviours in a small case series of East African migrants in Melbourne. Australian and New Zealand Journal of Public Health, 36(6), 586-587.

Hughes, C. E., Lancaster, K., \& Spicer, B. (2011). How do Australian news media depict illicit drug issues? An analysis of print media reporting across and between illicit drugs, 2003-2008. International Journal of Drug Policy, 22(4), 285-291.

Hugo, G. (2009). Migration between Africa and Australia: a demographic perspective. Sydney: Australian Human Rights Commission.

Jackson, A. (2007, 13 October 2007). For refugees, it's been a hard, dazed journey into the light, The Age, p. 8. http://www. theage.com.au/news/national/for-refugees-its-been-a-hard-dazedjourney-into-the-light/2007/10/12/1191696179105.html

Jakubowicz, A. (2004). A Quintessential Collision: Vietnamese in Australia after a generation of settlement and adaptation. https://andrewjakubowicz.com/public ations/vietnamese-in-australiaa-quintessential-collision/

Khawar, L., \& Rowe, R. (2013). Substance use issues and support needs among CALD communities in NSW: Report from DAMEC Research 
Strategy Consultation. Sydney: Drug and Alcohol Multicultural Education Centre.

Kline, K. N. (2006). A decade of research on health content in the media: The focus on health challenges and sociocultural context and attendant informational and ideological problems. Journal of Health Communication, 11(1), 43-59.

Lancaster, K., Hughes, C. E., \& Spicer, B. (2012). Media ownership and content diversity: reporting of illicit drug issues in NSW, VIC, ACT and WA major metropolitan daily newspapers. Australian Journalism Review, 34(1), 53-66.

Lancaster, K., Hughes, C. E., Spicer, B., Matthew-Simmons, F., \& Dillon, P. (2011). Illicit drugs and the media: Models of media effects for use in drug policy research. Drug and Alcohol Review, 30(4), 397402.

Madden, A. (2008). 'It's My Life': Ethics in Consumer Research. Of Substance: The National Magazine on Alcohol, Tobacco and Other Drugs, 6(2), 28.

Manton, E., Pennay, A., \& Savic, M. (2014). Public drinking, social connection and social capital: A qualitative study. Addiction Research \& Theory, 22(3), 218-228.

Mapedzahama, V., \& Kwansah-Aidoo, K. (2013). Negotiating Diasporic Black African Existence in Australia: A Reflexive Analysis. Australasian Review of African Studies, 34(1), 61-80.

Markus, A. (2013). Mapping Social Cohesion: The Scanlon Foundation Surveys, Recent Arrivals Report 2013. Caulfield East: Monash University.

Marlowe, J., Harris, A., \& Lyons, T. (Eds.). (2013). South Sudanese Diaspora in Australia and New Zealand: Reconciling the Past with the Present. Newcastle upon Tyne, UK: Cambridge Scholars Publishing.

Marlowe, J. M. (2010). Beyond the Discourse of Trauma: Shifting the Focus on Sudanese Refugees. Journal of Refugee Studies, 23(2), 183-198.

Masanauskas, J., \& Mickelburough, P. (2006, 13 February 2006). Driver is sorry for boy's pain, Herald Sun, p. 6.

McDonald, D. (2014). Consumer participation in the Australian alcohol and other drug sector. Canberra: Australian National Council on Drugs.

McIlveen, L. (2006, 16 March 2006). Migrant Sham: Refugee keeps visa despite teen sex conviction, Daily Telegraph, p. 1. 
Morgan, G., \& Idriss, S. (2012). 'Corsages on their parents' jackets': employment and aspiration among Arabic-speaking youth in Western Sydney. Journal of Youth Studies, 15(7), 929-943.

Morris, M. D., Popper, S. T., Rodwell, T. C., Brodine, S. K., \& Brouwer, K. C. (2009). Healthcare Barriers of Refugees Post-resettlement. Journal of Community Health, 34(6), 529-538.

Munro, I. (2010, 6 December 2010). Refugee denied citizenship, The Age, p. 5. http://www.theage.com.au/victoria/refugee-denied-citizenship20101205-18lch.html

Murray, S. B., \& Skull, S. A. (2005). Hurdles to health: immigrant and refugee health care in Australia. Aust Health Review, 29(1), 25-29.

Ndlovu-Gatsheni, S. J. (2010). Do 'Africans' exist? Genealogies and paradoxes of African identities and the discourses of nativism and xenophobia. African Identities, 8(3), 281-295.

Nicholls, J. (2011). UK news reporting of alcohol: An analysis of television and newspaper coverage. Drugs: Education, Prevention \& Policy, 18(3), 200-206.

Nunn, C. (2010). Spaces to Speak: Challenging Representations of Sudanese-Australians. Journal of Intercultural Studies, 31(2), 183198.

Oakes, D. (2012, 13 July 2012). How the West was lost, The Age, p. 11. http://www.theage.com.au/victoria/how-the-west-was-lost20120712-21yo1.html

Papanastasiou, C., Higgs, P., \& Dietze, P. (2012). Public Drinking and Drug Use in the Footscray Central Business District: Report to Maribyrnong City Council. Melbourne: Burnet Institute.

Petrie, A. (2012, 8 November 2012). 'Alarming' alcohol abuse by African youths, The Age. http://www.theage.com.au/vic toria/alarmingalcohol-abuse-by-african-youths-20121107-28xqt.html

Phillips, G. (2009). Ethnic Minorities in Australia's Television News: A Second Snapshot. Australian Journalism Review, 31(1), 19-32.

Phillips, G. (ND). Reporting Diversity. http://www.reportingdiversity .org.au/

Phillips, M. (2011). Convenient labels, inaccurate representations: Turning Southern Sudanese Refugees into 'African-Australians'. Australasian Review of African Studies, 32(2), 57 -79.

Police assaulted by drunk. (2004, 1 Marcch 2004). Mooney Valley Gazette, p. 12.

Posselt, M., Galletly, C., de Crespigny, C., \& Procter, N. (2013). Mental health and drug and alcohol comorbidity in young people of refugee 
background: a review of the literature. Mental Health and Substance Use, 7(1), 19-30.

Reid, G., Crofts, N., \& Beyer, L. (2001). Drug Treatment Services for Ethnic Communities in Victoria, Australia: An examination of cultural and institutional barriers. Ethnicity and Health, 6(1), 13-26.

Reid, G., Higgs, P., Beyer, L., \& Crofts, N. (2002). Vulnerability among Vietnamese illicit drug users in Australia: challenges for change. Int J Drug Policy, 13(2), 127-136.

Reid, M., Farrelly, F., Farrell, L., Fry, T., \& Worsley, T. (2013). Drinkingrelated lifestyles: exploring the role of alcohol in Victorians' lives Qualitative research report. Melbourne: VicHealth.

Richards, I. (2014). Differences over difference: Journalism beyond the metropolis. Australian Journalism Review, 36(1), 5-14.

Roche, A. M., Bywood, P., T., F., Pidd, K., Borlagdan, J., \& Trifonoff, A. (2009). The Social Context of Alcohol Use in Australia. Adelaide: National Centre for Education and Training on Addiction.

Ross, N. (2006, 14 February 2006). Appeal likely against school crash driver, Herald Sun, p. 10.

Saguy, A. C., Frederick, D., \& Gruys, K. (2014). Reporting risk, producing prejudice: How news reporting on obesity shapes attitudes about health risk, policy, and prejudice. Social Science and Medicine, 111, 125-133.

Scanlon Foundation. (2016). Multiculturalism Discussion Paper. Melbourne: Scanlon Foundation.

Teo, P. (2000). Racism in the News: A Critical Discourse Analysis of News Reporting in Two Australian Newspapers. Discourse \& Society, 11(1), 7-49.

Tobin, C., Moodie, R., \& Livingstone, C. (2011). A review of public opinion towards alcohol controls in Australia. BMC Public Health, 11, 58.

Vaismoradi, M., Turunen, H., \& Bondas, T. (2013). Content analysis and thematic analysis: Implications for conducting a qualitative descriptive study. Nursing and Health Sciences, 15, 398-405.

van Dijk, T. A. (2011). Teaching Ethnic Diversity in Journalism School. GRITIM-UPF (Interdisciplinary Research Group on Immigration) Working Paper No.7. Barcelona: Universitat Pompeu Fabra.

Viruell-Fuentes, E. A., Miranda, P. Y., \& Abdulrahim, S. (2012). More than culture: Structural racism, intersectionality theory, and immigrant health. Social Science and Medicine, 75(12), 2099-2106. 
Wakefield, M., Flay, B., Nichter, M., \& Giovino, G. (2003). Role of the media in influencing trajectories of youth smoking. Addiction, 98(s1) 79-103.

Windle, J. (2008). The racialisation of African youth in Australia. Social Identities, 14(5), 553-566.

Wright, C. (2010). Othering difference: framing identities and representation in black children's schooling in the British context. Irish Educational Studies, 29(3), 305-320.

Zetter, R. (2007). More Labels, Fewer Refugees: Remaking the Refugee Label in an Era of Globalization. Journal of Refugee Studies, 20(2), 172-192. 